13

\title{
Теория термоэлектронной эмиссии скандатных катодов
}

\author{
() В.И. Капустин, ${ }^{1,2}$ И.П. Ли, А.В. Шуманов, ${ }^{1,2}$ С.О. Москаленко ${ }^{1,2}$ \\ ${ }^{1}$ МИРЭА - Российский технологический университет, \\ 119454 Москва, Россия \\ ${ }^{2} \mathrm{AO}$ „Плутон“, \\ 105120 Москва, Россия \\ e-mail: kapustin@mirea.ru
}

Поступило в Редакцию 15 апреля 2019 г.

В окончательной редакции 15 апреля 2019 г.

Принято к публикации 20 мая 2019 г.

С учетом определяющей роли кислородных вакансий в формировании термоэмиссионных свойств кристаллитов оксида бария, экспериментально показано и теоретически обосновано влияние микропримесей в оксиде бария на параметры его электронной структуры и, соответственно, на величину работы выхода. Установлено, что микропримеси скандия в кристаллитах оксида бария в зависимости от размеров кристаллитов в наноразмерной области приводят к формированию на поверхности кристаллитов доменов различных типов, обогащенных атомами скандия и характеризующихся пониженной работой выхода. Предложена физическая модель и проведены теоретические расчеты зависимости работы выхода доменов от температуры и концентрации кислородных вакансий в кристаллитах оксида бария, легированных атомами скандия, для различных типов доменов. Сформулирована экспериментальная методика, позволяющая физически корректно определять эмиссионные свойства скандатных катодов.

Ключевые слова: термоэлектронная эмиссия, скандатный катод, оксид бария, структура поверхности оксида, кислородные вакансии.

DOI: 10.21883/JTF.2020.01.48679.165-19

\section{Введение}

Во многих типах электровакуумных СВЧ приборов используют металлопористые катоды в виде вольфрамовой губки, поры которой заполнены алюминатом бариякальция. Плотность тока термоэмиссии такого катода при температуре $1050-1100^{\circ} \mathrm{C}$ достигает $15 \mathrm{~A} / \mathrm{cm}^{2}[1,2]$, при этом эмиссионные свойства катода определяются кристаллитами оксида бария, которые формируются в нем в результате термического активирования катода.

В литературе имеется множество публикаций о свойствах скандатных катодов - металлопористых катодах, дополнительно содержащих скандий в виде оксида или интерметаллида скандия, которые обеспечивают получение плотности тока катода до $100 \mathrm{~A} / \mathrm{cm}^{2}$, а в „рекордных“ случаях - до $400 \mathrm{~A} / \mathrm{cm}^{2}$ [3-6]. Такие характеристики скандатных катодов открывают возможности создания принципиально новых типов электровакуумных СВЧ приборов. Основными недостатками скандатных катодов являются плохая воспроизводимость технологий их изготовления, не обеспечивающая получение воспроизводимых и стабильных термоэмиссионных свойств катодов. До настоящего времени в литературе отсутствует теория скандатных катодов, адекватно описывающая их эмиссионные свойства и позволяющая сформулировать требования на оптимальный характер их структуры и технологии изготовления, обеспечивающей формирование такой структуры.
Задача создания промышленных образцов катодов со „скандатной“ плотностью тока термоэлектронной эмиссии подразумевает ответ на следующие вопросы:

- какой структурой поверхности должен обладать скандатный катод, чтобы обеспечить плотность тока термоэмиссии до $300-400 \mathrm{~A} / \mathrm{cm}^{2}$;

- какая технология может обеспечить формирование такой структуры поверхности скандатного катода;

- какие физико-химические процессы в материале катода в процессе его изготовления и срока службы могут обеспечить стабильность структуры поверхности катода и, соответственно, стабильность его термоэмиссионных свойств.

Настоящая работа посвящена разработке теории скандатных катодов, основанной на представлениях об определяющей роли кислородных вакансий и роли микропримесей в формировании эмиссионных свойств оксидов $[7,8]$, т. е. призвана ответить на первый из сформулированных выше вопросов.

\section{Экспериментальное обоснование теории}

На рис. 1, $a$ приведена энергетическая схема оксида бария, содержащего только кислородные вакансии, которые в объеме оксиде бария являются дефектами донорного типа, а на поверхности - дефектами акцепторного типа [8]. Так как кислородные вакансии в объеме расположены неупорядоченно, то в соответствии с 

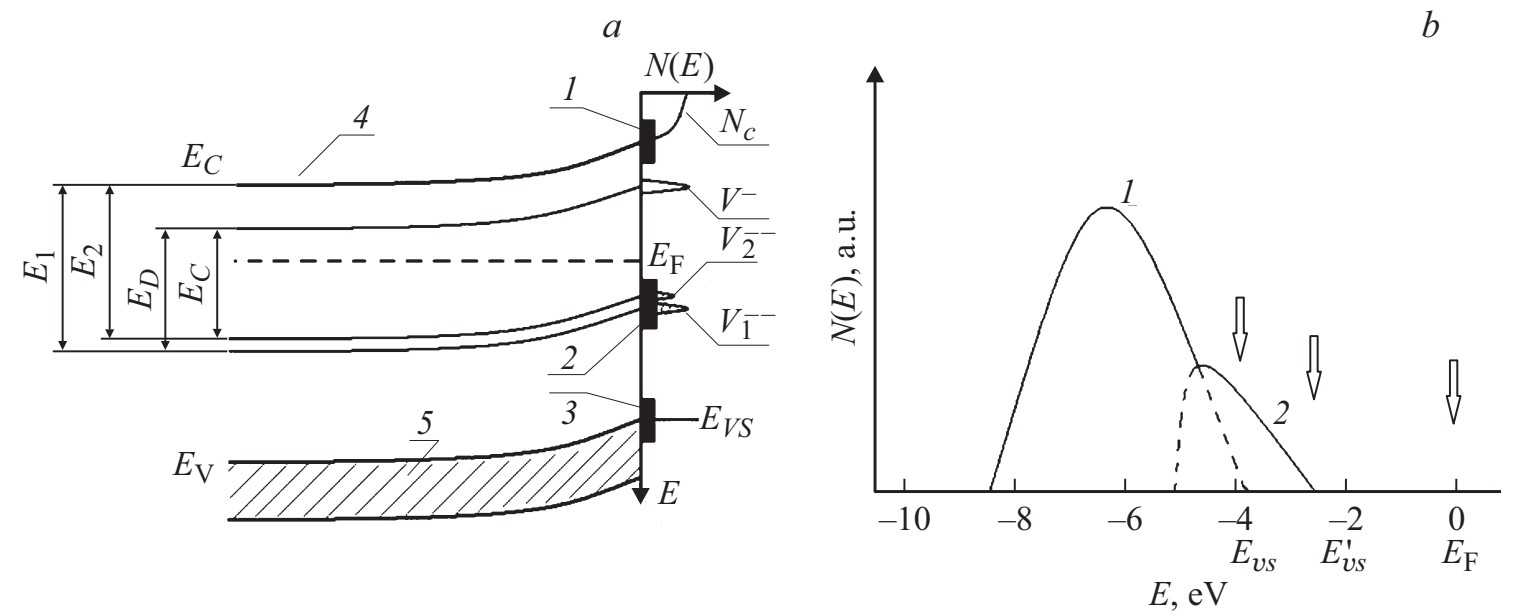

Рис. 1. Структура верхних энергетических зон оксида бария $(a)$ и структура плотности состояний валентной зоны $(b)$.

теорией неупорядоченных систем основной уровень кислородных вакансий расщепляется на две подзоны [8]. На рис. 1, $а$ обозначено: 1 и 3 - собственные поверхностные состояния оксида, 2 - поверхностные состояния, связанные с кислородными вакансиями, 4 - зона проводимости, 5 - валентная зона, $E_{C}-$ уровень дна зоны проводимости, $E_{V}$ и $E_{V S}-$ уровень верха валентной зоны в объеме и на поверхности оксида соответственно, $N_{C}$ - плотность состояний в зоне проводимости, $V_{1}^{--}$и $V_{2}^{--}$- плотности состояний соответственно в нижней и верхней подзонах двузарядной кислородной вакансии, $V^{-}$- плотность состояний однозарядной кислородной вакансии, $E_{\mathrm{F}}-$ уровень Ферми, $E_{1}, E_{2}, E_{D}$ и $E_{C}-$ энергии переходов между соответствующими электронными уровнями при оптическом возбуждении.

В работах $[9,10]$ было установлено, что микропримеси в кристаллитах оксида бария влияют на величину расщепления уровня кислородных вакансий и на смещение валентной зоны за счет появления в ней дополнительной зоны, как показано на рис. $1, b$. На рис. $1, b$ обозначено: 1 - основная валентная зона, 2 - область дополнительной зоны, сформированной электронами микропримесей, $E_{V S}-$ положение верхнего края дополнительной области валентной зоны.

На рис. 2, a приведены сводные экспериментальные данные $[9,10]$ по величине расщепления электронного уровня кислородных вакансий $\Delta=\left(E_{C}-E_{D}\right)=$ $=\left(E_{1}-E_{2}\right)$ в зависимости от ионного радиуса легирующего элемента $R_{i}$ относительно ионного радиуса бария $R_{\mathrm{Ba}}$, а на рис. $2, b-$ сводные данные по зависимости параметра $\left(E_{V S}-E_{\mathrm{F}}\right)$ от относительного ионного радиуса микропримесей. Результаты рис. 2, а получены методом оптической спектроскопии, а рис. 2, $b-$ методом электронной спектроскопии для химического анализа. Из рис. 2 следует, что при величине ионного радиуса микропримесей, лежащего в интервале $0.5-0.7$ от ионного радиуса бария, имеет место повышенная по сравнению с другими микропримесями их растворимость в
Относительные интенсивности пиков в оже-спектрах

\begin{tabular}{c|c|c|c}
\hline \multirow{2}{*}{$\begin{array}{c}\text { Пики элементов при } \\
\text { энергии, eV }\end{array}$} & \multicolumn{2}{|c|}{ W-Rе-матрица } & W-матрица \\
\cline { 2 - 4 } & $\begin{array}{c}\text { Исход- } \\
\text { ный }\end{array}$ & $\begin{array}{c}\text { Активи- } \\
\text { рованный }\end{array}$ & $\begin{array}{c}\text { Активи- } \\
\text { рованный }\end{array}$ \\
\hline$\frac{\mathrm{Sc}(336 \mathrm{eV})}{\mathrm{Ba}(75 \mathrm{eV})+\mathrm{Ba}(68 \mathrm{eV})}$ & 0.70 & 0.69 & 0.72 \\
\hline$\frac{\mathrm{Ba}(75 \mathrm{eV})}{\mathrm{Ba}(68 \mathrm{eV})}$ & 0.83 & 0.70 & 0.60 \\
\hline$\frac{\mathrm{Sc}(336 \mathrm{eV})}{\mathrm{Ba}(75 \mathrm{eV})}$ & 1.53 & 1.67 & 1.93 \\
\hline$\frac{\mathrm{Sc}(336 \mathrm{eV})}{\mathrm{Ba}(68 \mathrm{eV})}$ & 1.27 & 1.17 & 1.16
\end{tabular}

оксиде бария с формированием дополнительной области в валентной зоне, а также упорядочение кислородных вакансий в объеме оксида бария, что проявляется в уменьшении параметра беспорядка $\Delta$.

В работе [6] методом оже-спектроскопии были исследованы скандатные катоды с матрицами из вольфрама и вольфрам-рения. В таблице приведены выполненные нами результаты обработки интенсивностей пиков в оже-спектрах, приведенных в работе [6]. Пик бария при энергии $75 \mathrm{eV}$ относится к состоянию с пониженной степенью окисления, т. е. к барию рядом с кислородной вакансией, а пик бария при энергии $68 \mathrm{eV}$ - к барию в оксиде бария. В работе [6] был использован спектрометр с энергоанализатором цилиндрического типа, разрешающей способности которого оказалось недостаточно для разделения пика скандия с различной степенью окисления скандия. Как видно из таблицы, при активировании скандатного катода содержание скандия на поверхности относительно суммарного содержания бария сохраняется, однако имеет место перераспределение содержания 

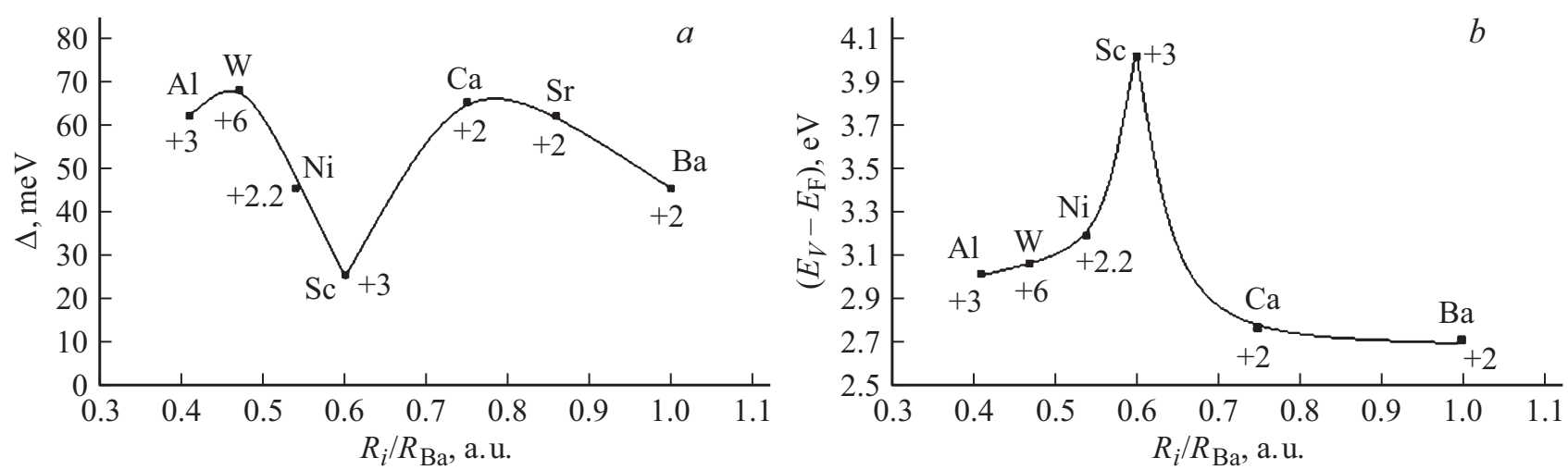

Рис. 2. Зависимость величины расщепления уровня кислородных вакансий $(a)$ и величины смещения верха валентной зоны $(b)$ от относительного ионного радиуса легирующей примеси в оксиде бария.

бария в различных степенях окисления, т. е. изменение концентрации кислородных вакансий на поверхности оксида бария.

В работе [11] с использованием эмиссионного микроскопа при увеличении 4000 было показано, что структура поверхности скандатного катода имеет доменный характер со средним расстоянием между доменами $300 \mathrm{~nm}$ и средним размером доменов $28 \mathrm{~nm}$ при среднем размере пор, заполненных эмиссионно-активным веществом, порядка 5-10 $\mu \mathrm{m}$. Поэтому результаты [11], а также приведенные выше результаты показывают, что на поверхности эмиссионно-активной фазы в скандатном катоде в результате его активирования формируются домены c повышенной концентрацией скандия и пониженной поверхностной концентрацией кислородных вакансий. Отметим, что в работе [11] величину работы выхода скандатного катода по результатам измерения вольтамперных характеристик рассчитывали с использованием известного метода „прямых Ричардсона“, что, на наш взгляд, является недостаточно корректным, так как данный метод применим для металлов и сплавов, а для катодных материалов на основе оксидов, являющихся полупроводниками донорного типа, корректнее применять метод „полного тока“.

\section{Модель структуры поверхности скандатного катода}

На рис. 3 приведена обобщенная схема структуры поверхности кристаллитов оксида бария в скандатном катоде. На рис. 3 обозначены положения атомов кислорода: 1 - вблизи поверхностного атома Ва во втором монослое; $1^{\prime}$ - вблизи поверхностного атома Sc во втором монослое; 2 - между атомами Ва в первом монослое; 2' - между атомами $\mathrm{Sc}$ и $\mathrm{Ba}$ в первом монослое; 2" - между двумя атомами Sc в первом монослое; 3 - атома кислорода, адсорбированного на атоме $\mathrm{Ba} ; 3^{\prime}$ - атома кислорода, адсорбированного на атоме Sc; 4 - атома кислорода в объеме кристаллита

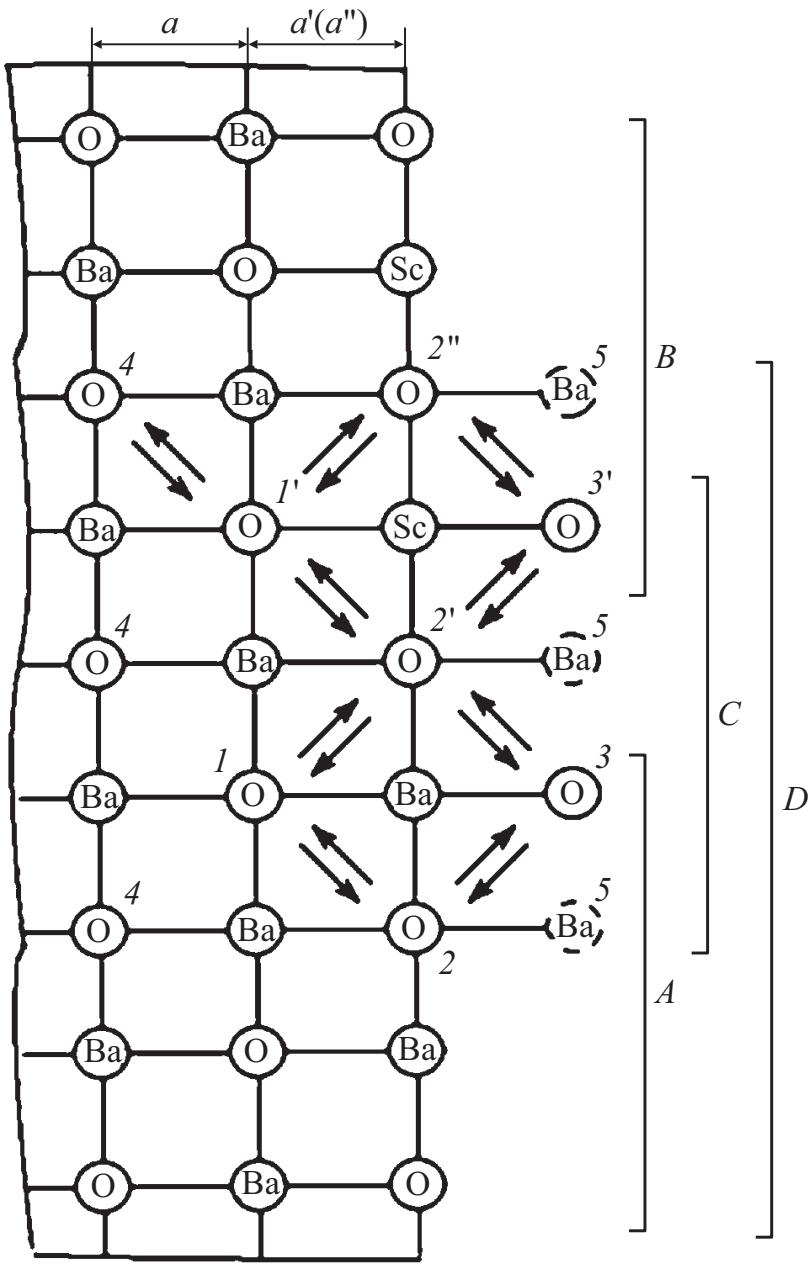

Рис. 3. Возможные варианты структуры поверхности кристаллитов оксида бария в скандатном катоде.

$\mathrm{BaO}, 5$ - атома Ва, адсорбированного на атоме кислорода. Кислородные узлы кристаллической решетки могут быть либо заняты атомами кислорода, либо вакантными. Стрелками на рис. 3 показаны возможные переходы атомов кислорода из занятых в вакантные узлы. Справа 
квадратными скобками указаны возможные варианты структуры поверхности: $A$ - кристаллиты чистого оксида бария без скандия, $B$ - поверхностные домены из атомов скандия и кислорода, $C$ - поверхностные домены из чередующихся атомов скандия, кислорода и бария, $D$ - поверхностные домены с содержанием атомов скандия, соответствующим его объемному содержанию, которое по данным работы [11] можно оценить величиной $0.7 \%$.

На рис. 4 приведена диаграмма энергии связи атомов кислорода в чистом $\mathrm{BaO}$ (сплошная) и в $\mathrm{BaO}$ с внедренным атомом Sc на поверхности (штриховая). Цифры на рис. 4 соответствуют положениям атомов кислорода в узлах кристаллической решетки на рис. 3. Из-за наличия оборванных химических связей справа от верхнего поверхностного монослоя на рис. 3, в общем случае должны выполняться соотношения для межплоскостных расстояний $a^{\prime}<a$; $a^{\prime \prime}<a$, где $a-$ межплоскостное расстояние в объеме оксида бария, $a^{\prime}$ - межплоскостное расстояние на поверхности чистого оксида бария, $a^{\prime \prime}$ - межплоскостное расстояние на поверхности при наличии на ней атомов скандия. При этом значение параметра $a$ для нанокристаллитов $\mathrm{BaO}$ будет меньше его значения для массивного $\mathrm{BaO}$, а отклонение значений $a^{\prime}$ и $a^{\prime \prime}$ от параметра $a$ для нанокристаллитов $\mathrm{BaO}$ будет различным из-за различия ионных радиусов бария и скандия. Так как ионный радиус скандия меньше ионного радиуса бария, то можно ожидать, что энергетически выгодным будет соотношение $a^{\prime \prime}<a^{\prime}$. Физически это означает, что энергетически выгодным будет формирование на поверхности нанокристаллитов $\mathrm{BaO}$ доменов с поверхностными атомами скандия в верхнем монослое $\mathrm{BaO}$, при этом значения энергии связи атома кислорода в положениях 1-3 на рис. 4 изменятся соответственно на величину $\Delta E_{1}, \Delta E_{2}$ и $\Delta E_{3}$.

Изменения энергии связи атома кислорода вблизи атома скандия относительно ее значения вблизи атома бария можно оценить по величине энтальпии образования оксидов бария и скандия на одну связь барий-кислород в оксиде бария, равную $2.9 \mathrm{eV}$, или

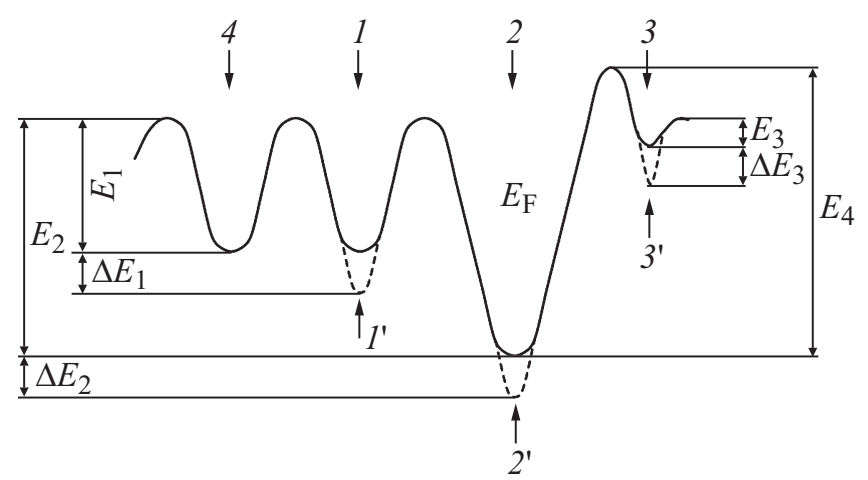

Pис. 4. Диаграмма энергии связи атомов кислорода в чистом $\mathrm{BaO}$ (сплошная) и в $\mathrm{BaO}$ с внедренным атомом $\mathrm{Sc}$ на поверхности (штриховая).

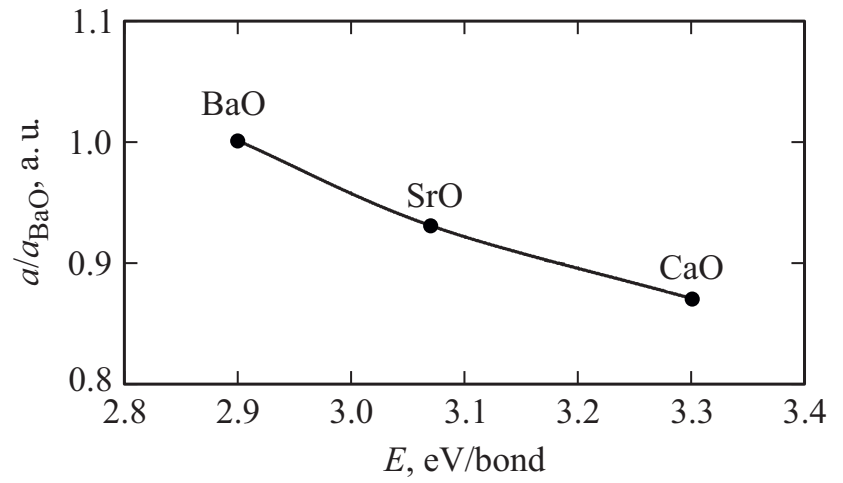

Рис. 5. Соотношение между энтальпией на одну связь при образовании оксидов $\mathrm{BaO}, \mathrm{CaO}, \mathrm{SrO}$ и параметром кристаллической решетки оксидов.

скандий-кислород в оксиде скандия, равную $3.3 \mathrm{eV}$ [12]. Поэтому величина $\Delta E_{1}$ для атома кислорода во втором монослое вблизи атома скандия будет равна $0.4 \mathrm{eV}$, величина $\Delta E_{3}$ для адсорбированного на атоме скандия кислорода будет равна $0.4 \mathrm{eV}$, а величину $\Delta E_{2}$ можно принять равной $0.4 \mathrm{eV}$ для атома кислорода у изолированного атома скандия в положении $2^{\prime}$, и равной $0.8 \mathrm{eV}$, если атом кислорода в верхнем монослое находится между двумя атомами скандия в положении $2^{\prime \prime}$, так как у такого атома кислорода меняются сразу две связи.

Параметры $E_{1}, E_{2}$ и $E_{4}$ на обозначенных сплошной линией кривых потенциальной энергии атома кислорода в чистом оксиде бария имеют смысл энергии активации переходов атомов кислорода в соседние свободные узлы кристаллической решетки на рис. 3 через потенциальные барьеры. Из-за наличия оборванных химических связей на поверхности кристалла $\mathrm{BaO}$ при $a^{\prime}<a$ должно выполняться соотношение $\left(E_{2}-E_{1}\right)>0$. На рис. 5 приведено соотношение между энтальпией на одну связь при образовании оксидов $\mathrm{BaO}, \mathrm{CaO}, \mathrm{SrO}$, имеющих однотипные кристаллические структуры, и параметром кристаллической решетки массивных кристаллов указанных оксидов. Видно, что с увеличением энергии связи между ионами металла и кислорода кристаллическая решетка „сжимается“. На рис. 3 у атома кислорода в положении 2 или $2^{\prime}$ справа отсутствует атом бария, вместо которого имеется оборванная связь. Именно отсутствие этих электроположительных ионов и приводит к соотношениям $\left(E_{4}-E_{2}\right)>0$; $\left(E_{4}-E_{1}\right)>0$.

\section{Концентрация кислородных вакансий на поверхности}

В соответствии с теорией абсолютных скоростей реакций [13] скорость каждого перехода, обозначенного 
стрелкой на рис. 3, будет равна

$$
v=\frac{k T}{\hbar} C_{A} P_{B} \frac{f_{\ddagger}}{f_{A} f_{B}} \exp (-\varepsilon / R T),
$$

где $C_{A}$ - концентрация атомов кислорода в положении $A ; P_{B}$ - вероятность того, что положение $B$ занято вакансией; $f_{A}$ и $f_{B}-$ суммы состояний атома $A$ и вакансии $B ; f_{\ddagger}-$ сумма состояний активированного атома $A$ на вершине потенциального барьера между состояниями $A$ и $B ; \varepsilon-$ энергия активации перехода, равная по величине потенциальному барьеру между состояниями $A$ и $B ; k-$ постоянная Больцмана; $\hbar-$ постоянная Планка; $T$ - температура. Для всех переходов, обозначенных стрелками на рис. 3 , величина

$$
A=\frac{k T}{\hbar} \frac{f_{\ddagger}}{f_{A} f_{B}}
$$

одинакова. Поэтому относительная скорость переходов имеет вид

$$
v^{\prime}=C_{A} P_{B} \exp \left(-\frac{\varepsilon}{k T}\right) .
$$

С учетом наличия (скандатный катод) или отсутствия (металлопористый катод) атомов скандия, растворенных в кристаллитах оксида бария, а также с учетом влияния размера кристаллитов на параметр кристаллической решетки в его объеме или межплоскостного расстояния между первым и вторым поверхностными монослоями кристаллита, могут иметь место четыре варианта структуры поверхности кристаллитов, обозначенные на рис. 3 как варианты структуры $A, B, C$ и $D$.

В варианте А в кристаллитах отсутствуют примесные атомы скандия, при этом поверхностная концентрация кислородных вакансий находится из равенства скоростей переходов между состояниями в соответствии с рис. 3 по уравнению

$$
(2 \rightarrow 1)+(2 \rightarrow 3)=(1 \rightarrow 2)+(3 \rightarrow 2) .
$$

В результате выражение для поверхностной концентрации кислородных вакансий $N_{S}(A)$ имеет вид, полученный ранее в работах $[7,8]$

$$
N_{S}(A)=N_{S O} \exp \left(-\frac{E_{4}-E_{1}}{k T}\right)+a N_{D} \exp \left(-\frac{E_{2}-E_{1}}{k T}\right) .
$$

В выражении (5) $N_{S O}$ - поверхностная плотность кислородных узлов, $N_{D}$ - объемная концентрация кислородных вакансий, сформированная на этапе активирования катода. Выражение (5) справедливо при малости концентрации кислорода в положении 3 и отсутствии атомов бария в положении 5. Если данные условия не выполняются, это означает просто появление дополнительного монослоя на поверхности кристаллита $\mathrm{BaO}$, содержащего кислородные вакансии. При численных расчетах, результаты которых ниже использованы для нахождения величины искривления зон, в соотношении (5) было принято: $\left(E_{4}-E_{1}\right)=0.8 \mathrm{eV} ;\left(E_{2}-E_{1}\right)=0.5 \mathrm{eV}$;
$\left(E_{4}-E_{2}\right)=0.3 \mathrm{eV} ; a=5.52 \cdot 10^{-10} \mathrm{~m} ; N_{S O}=3.28 \cdot 10^{-18} \mathrm{~m}^{-2}$. Данные значения указанных параметров обеспечивают хорошее согласие расчетных и экспериментальных данных для плотности тока термоэмиссии чистого оксида бария $[7,8]$.

В варианте В все поверхностные узлы катиона заняты атомами скандия, т. е. на поверхности кристаллита $\mathrm{BaO}$ сформировались домены с поверхностными атомами скандия. Такой случай может иметь место для наноразмерных кристаллитов оксида бария, для которых параметр $a^{\prime \prime}$ существенно меньше параметра $a$, который, в свою очередь, меньше параметра кристаллической решетки для массивного кристалла оксида бария. Для этого случая поверхностная концентрация кислородных вакансий может быть определена из уравнений равновесия для узлов $1^{\prime}$ и $2^{\prime \prime}$, которые имеют вид соответственHO

$$
\begin{aligned}
\left(4 \rightarrow 1^{\prime}\right)+\left(2^{\prime \prime} \rightarrow 1^{\prime}\right) & =\left(1^{\prime} \rightarrow 4\right)+\left(1^{\prime} \rightarrow 2^{\prime \prime}\right), \\
\left(2^{\prime \prime} \rightarrow 1^{\prime}\right)+\left(2^{\prime \prime} \rightarrow 3^{\prime}\right) & =\left(1^{\prime} \rightarrow 2^{\prime \prime}\right)+\left(3^{\prime} \rightarrow 2^{\prime \prime}\right) .
\end{aligned}
$$

Для этого случая $\Delta E_{1}=0.4 \mathrm{eV} ; \Delta E_{2}=0.8 \mathrm{eV}=2 \Delta E_{1}$, и в итоге выражение для поверхностной концентрации кислородных вакансий $N_{S}(B)$ имеет вид

$$
\begin{aligned}
N_{S}(B) & =\left[N_{S O} \exp \left(-\frac{E_{4}-E_{1}+\Delta E_{2}-\Delta E_{1}}{k T}\right)\right. \\
& \left.+a N_{D} \exp \left(-\frac{E_{2}-E_{1}+\Delta E_{1}}{k T}\right)\right] .
\end{aligned}
$$

С учетом соотношения (5) выражение (8) можно записать в виде

$$
N_{S}(B)=N_{S}(A) \cdot \exp \left(-\frac{\Delta E_{1}}{k T}\right),
$$

т. е. для варианта $B$ концентрация кислородных вакансий на поверхности существенно меньше, чем для варианта $A$, причем это различие зависит от температуры.

В варианте $\mathbf{C}$, если размер кристаллитов $\mathrm{BaO}$ возрастает по сравнению с размером кристаллитов в варианте $B$, может иметь место чередование атомов бария и скандия в верхнем монослое кристаллитов, т. е. формируется домен с поверхностным чередованием катионов различного типа и с различающимися ионными радиусами. Для этого случая выполняется тождество $2^{\prime} \equiv 2^{\prime \prime}$ и уравнения равновесия для узлов $1^{\prime}$ и $2^{\prime}$ имеют вид

$$
\begin{aligned}
\left(4 \rightarrow 1^{\prime}\right)+\left(2^{\prime} \rightarrow 1^{\prime}\right) & =\left(1^{\prime} \rightarrow 4\right)+\left(1^{\prime} \rightarrow 2^{\prime}\right) \\
\left(1^{\prime} \rightarrow 2^{\prime}\right)+\left(1 \rightarrow 2^{\prime}\right) & =\left(2^{\prime} \rightarrow 1^{\prime}\right)+\left(2^{\prime} \rightarrow 1\right) \\
& +\left(2^{\prime} \rightarrow 3^{\prime}\right)+\left(2^{\prime} \rightarrow 3\right)
\end{aligned}
$$

Ввиду малости концентрации адсорбированных атомов кислорода в положениях 3 и $3^{\prime}$, переходы $\left(3^{\prime} \rightarrow 2^{\prime}\right)$ и $\left(3 \rightarrow 2^{\prime}\right)$ в уравнении $(11)$ не учитывались. Так как 
для этого случая параметры $\Delta E_{2}=\Delta E_{1}=0.4 \mathrm{eV}$, то выражение для поверхностной концентрации кислородных вакансий будет иметь вид

$$
\begin{aligned}
N_{S}(C)= & r\left[N_{S O} \exp \left(-\frac{E_{4}-E_{1}+\Delta E_{2}}{k T}\right)\right. \\
& \left.+a N_{D} \exp \left(-\frac{E_{2}-E_{1}+\Delta E_{2}}{k T}\right)\right],
\end{aligned}
$$

причем с учетом соотношений (5), (8) и (9) выражение (12) можно записать в виде

$$
N_{S}(C)=4 N_{S}(B)=4 N_{S}(A) \cdot \exp \left(-\frac{\Delta E_{1}}{k T}\right) .
$$

В варианте D при малой концентрации атомов скандия $C$, растворенных в кристаллитах оксида бария, и при дальнейшем увеличении размера кристаллитов оксида бария концентрация кислородных вакансий на поверхности составит

$$
N_{S}(D)=C \cdot N_{S}(C)+(1-C) \cdot N_{S}(A),
$$

т. е. мало отличается от варианта $A$.

Таким образом, максимальная концентрация кислородных вакансий на поверхности кристаллитов оксида бария будет иметь место в варианте $A$, т.е. в чистом оксиде бария. Минимальная концентрация кислородных вакансий на поверхности кристаллитов оксида бария будет в варианте В при формировании доменов с поверхностными атомами скандия, а при формировании доменов со смешанным расположением атомов скандия и бария в варианте $C$ она будет в 4 раза больше, чем в варианте $B$. В варианте $D$ концентрация поверхностных кислородных вакансий будет мало отличаться от концентрации вакансий на поверхности в варианте $A$.

\section{Искривление энергетических зон у поверхности}

В соответствии с теорией поверхности ионных кристаллов [14], к классу которых относится и оксид бария, кислородные вакансии, которые в объеме оксида образуют донорный уровень в запрещенной энергетической зоне, на поверхности оксида формируют локализованные поверхностные состояния акцепторного типа, что приводит к искривлению энергетических зон оксида вверх. Искривление зон обусловлено зарядом локализованных поверхностных состояний с поверхностной плотностью $q_{s}=3^{*} \cdot N_{S}$, где $e^{*}-$ величина эффективного заряда кислородной вакансии, которая для простоты принята нами равной заряду электрона. В работах $[7,8]$ была предложена методика расчета величины искривле-
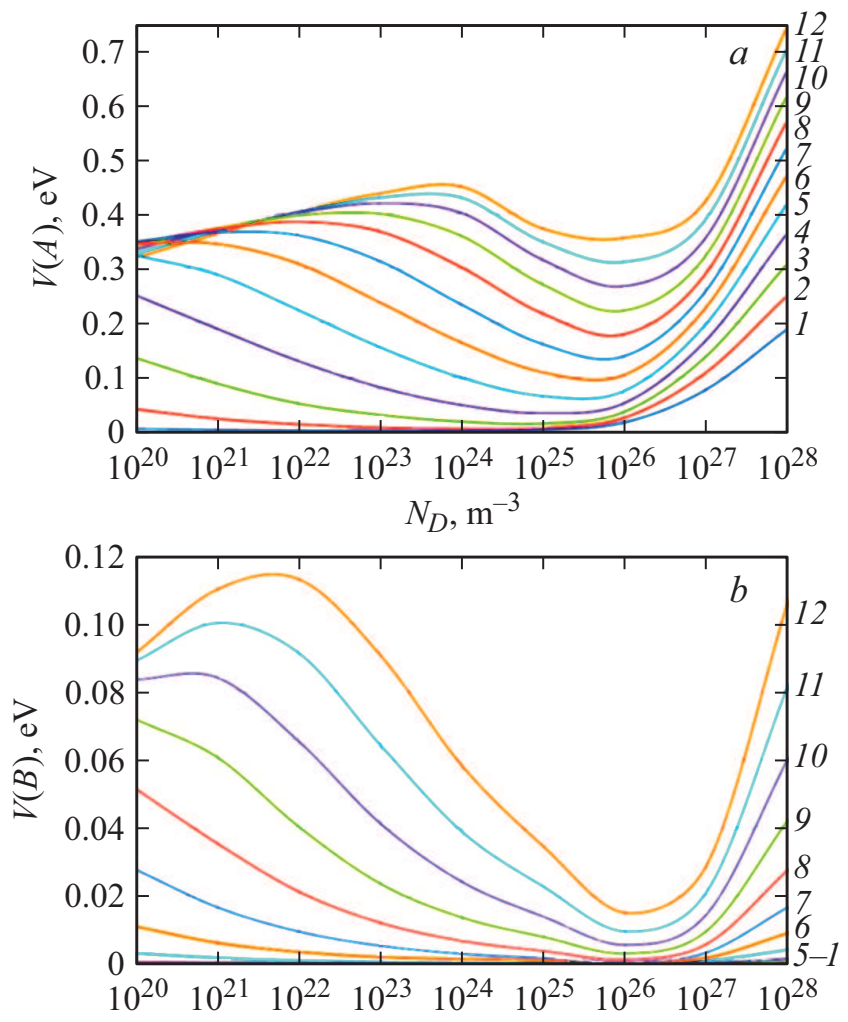

$N_{D}, \mathrm{~m}^{-3}$

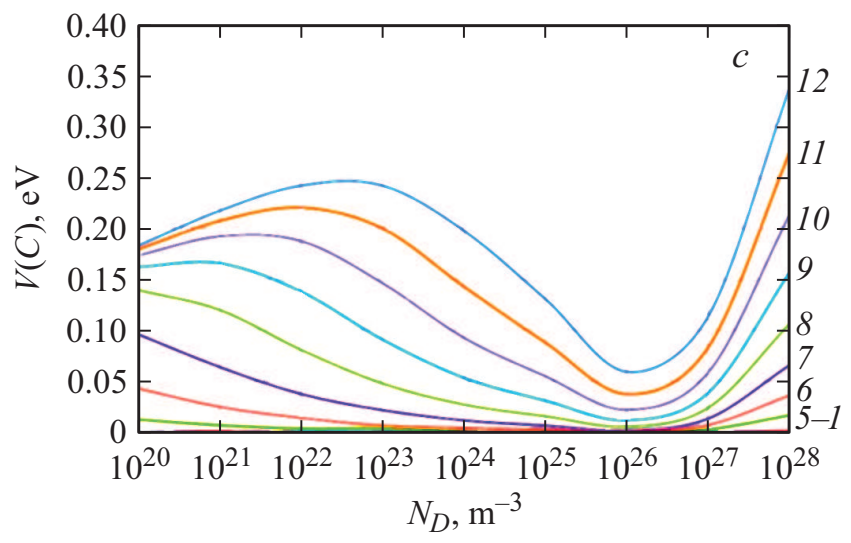

Рис. 6. Расчетные зависимости величины искривления зон оксида бария от концентрации кислородных вакансий при различных значениях температуры для вариантов структуры поверхности: $a-$ вариант $A, b-$ вариант $B, c-$ вариант $C$.

ния зон в соответствии с уравнением

$$
\begin{aligned}
& 2 \varepsilon \varepsilon_{0} k T \sqrt{\frac{N_{C} N_{D}}{2}} \exp \left(-\frac{\Delta E_{g}}{2 k T}\right) \\
& \times\left[\exp \left(\frac{V}{k T}\right)+\exp \left(-\frac{V}{k T}\right)-2\right] \\
& =\left[\frac{e^{*} N_{S}}{1+\sqrt{\frac{2 N_{C}}{N_{D}} \exp \left(-\frac{\Delta E_{g}-2 V}{k T}\right)}}\right]^{2},
\end{aligned}
$$


где $\varepsilon$ - диэлектрическая проницаемость оксида, $\varepsilon_{0}-$ диэлектрическая постоянная, $V$ - величина искривления энергетических зон у поверхности, $\Delta E_{g}-$ расстояние между уровнем кислородных вакансий и дном зоны проводимости в объеме оксида, $k-$ постоянная Больцмана, $T$ - температура, $N_{C}=2(2 \pi m k T / \hbar)^{3 / 2}-$ эффективное число состояний в зоне проводимости оксида, $m$ - масса электрона, $\hbar$ - постоянная Планка.

Для варианта А на рис. 6, $a$ приведены результаты численных расчетов зависимости величины $V(A)$ от концентрации кислородных вакансий в объеме $\mathrm{BaO}$ при различных значениях температуры: 1 - 400, 2 $500,3-600,4-700,5-800,6-900,7-$ $1000,8-1100,9-1200,10-1300,11-1400$, $12-1500 \mathrm{~K}$.

Для варианта В на рис. $6, b$ приведены расчетные зависимости величины искривления зон $V(B)$ в $\mathrm{BaO}$ от объемной концентрации кислородных вакансий $N_{D}$ при различных значениях температуры $T: 1-400$, $2-500,3-600,4-700,5-800,6-900$, $7-1000,8-1100,9-1200,10-1300,11-1400$, $12-1500 \mathrm{~K}$.

Для варианта $\mathbf{C}$ на рис. $6, c$ приведены расчетные зависимости величины искривления зон $V(C)$ в оксиде бария от объемной концентрации кислородных вакансий $N_{D}$ при различных значениях температуры $T: 1-400$, $2-600,3-800,4-900,5-1000$. $6-1100$, $7-1200,8-1300,9-1400,10-1500 \mathrm{~K}$.

Для варианта D расчетные зависимости величины искривления зон от концентрации кислородных вакансий в пределах погрешности менее $1 \%$ совпадают с результатами расчетов для варианта $A$.

\section{Работа выхода скандатного катода}

Для полупроводников с широкой запрещенной зоной, к классу которых относится большинство оксидов элементов IIA-IIIA подгрупп Периодической системы, величину работы выхода можно представить в виде суммы „внутренней“ и „внешней“ вклада в работу выхода величины искривления зон у поверхности оксида в виде выражения

$$
\varphi=\psi+\chi+V
$$

где $\psi$ - величина „внутренней“ работа выхода, равная

$$
\psi=\frac{\Delta E_{g}}{2}+k T \ln \left[\frac{2\left(2 \pi m^{*} k T\right)^{3 / 2}}{N_{D} \hbar^{8}}\right]^{1 / 2},
$$

$\hbar$ - постоянная Планка, $m^{*}$ - эффективная масса электрона, $\chi$ - величина электронного сродства оксида бария, принятая равной $0.8 \mathrm{eV}$.

Для варианта А на рис. 7, $a$ приведены результаты численных расчетов зависимости величины работы выхода $\varphi(A)$ чистого оксида бария от концентрации кислородных вакансий в объеме $\mathrm{BaO}$ при различных
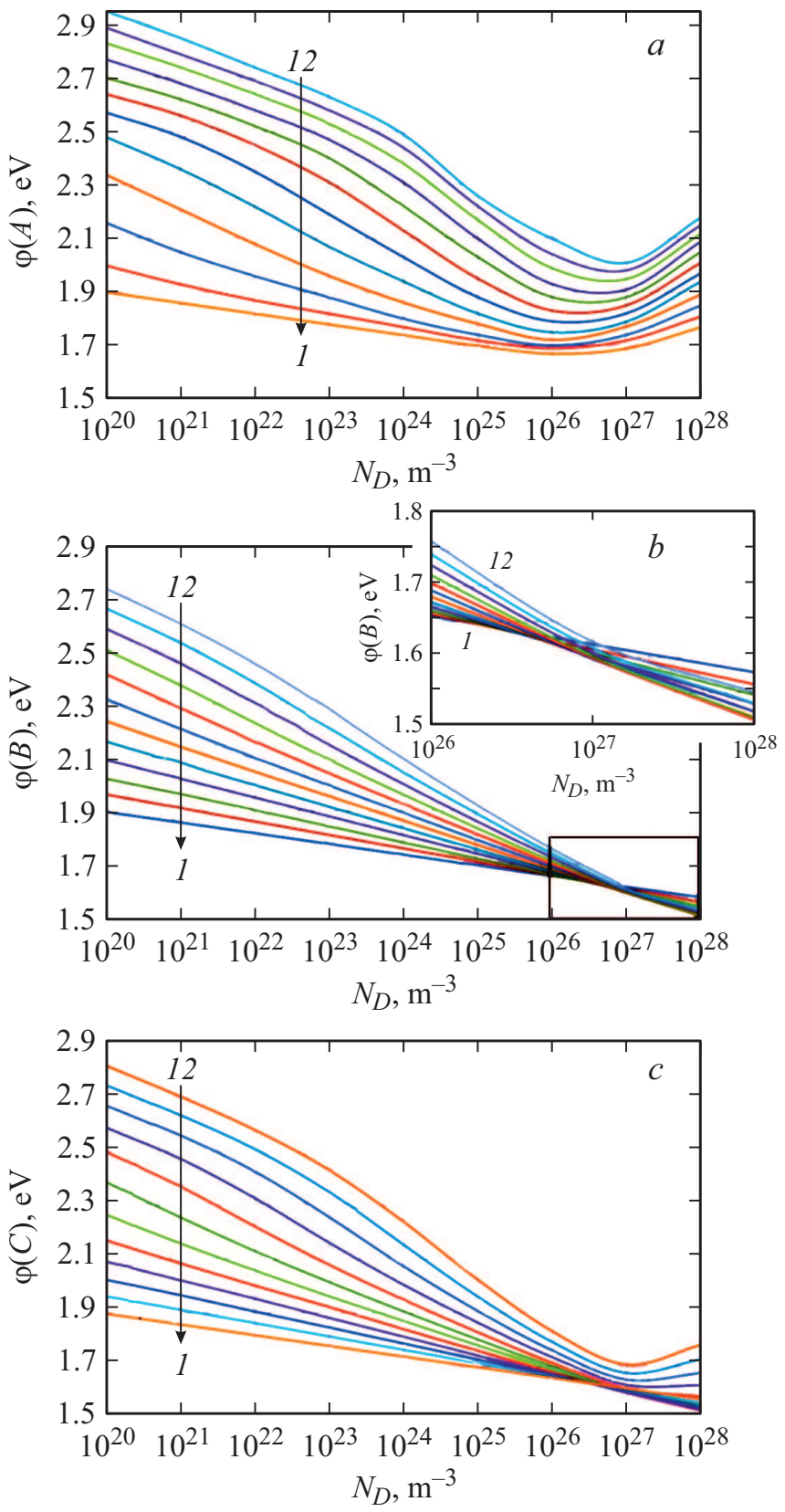

Рис. 7. Расчетные зависимости работы выхода оксида бария от концентрации кислородных вакансий при различных значениях температуры для вариантов структуры поверхности: $a$ - вариант $A, b-$ вариант $B, c-$ вариант $C$.

значениях температуры $T: 1-400,2-500,3-600$, $4-700,5-800,6-900,7-1000,8-1100$, $9-1200,10-1300,11-1400,12-1500$ К. Приведенные на данном рисунке результаты были впервые получены в работе [7].

Для варианта В на рис. 7, $b$ приведены расчетные зависимости работы выхода $\varphi(B)$ оксида бария от объемной концентрации кислородных вакансий $N_{D}$ при различных значениях температуры $T: 1-400,2-500,3-600$, $4-700,5-800,6-900,7-1000,8-1100$, 
$9-1200,10-1300,11-1400,12-1500 \mathrm{~K}$. Область концентраций $10^{26}-10^{28} \mathrm{~m}^{-1}$ более детально показана на вставке.

Для варианта $\mathbf{C}$ на рис. 7, $c$ приведены расчетные зависимости работы выхода $\varphi(C)$ оксида бария от объемной концентрации кислородных вакансий $N_{D}$ при различных значениях температуры $T: 1-600,2-800,3-1000$, $4-1200,5-1400,6-1500 \mathrm{~K}$. Область концентраций $10^{26}-10^{28} \mathrm{~m}^{-1}$ также более детально показана на вставке.

Для варианта D расчетные зависимости величины работы выхода от концентрации кислородных вакансий в пределах погрешности менее $1 \%$ совпадают с результатами расчетов для варианта $A$.

Как видно на рис. 7, характеры зависимостей величины работы выхода структур $A, B$ и $C$ от температуры и концентрации кислородных вакансий несколько различаются. При этом сравнение результатов расчетов работы выхода для вариантов $A, B$ и $C$ показывает, что для вариантов $B$ и $C$ в интервале температур $900-1000^{\circ} \mathrm{C}$ и интервале концентрации кислородных вакансий $1-5 \cdot 10^{26} \mathrm{~m}^{-3}$ величина работы выхода на $0.30-0.35 \mathrm{eV}$ меньше, чем для варианта $A$ структуры. Это означает, что в данном интервале температур плотность тока термоэмиссии структур $B$ и $C$ будет в 20-35 раз выше, чем плотность тока структуры $A$, т.е. для структур $B$ и $C$ с учетом усиления тока вследствие эффекта Шоттки, она может достигать $300-500 \mathrm{~A} / \mathrm{cm}^{2}$.

\section{Физикохимия и вольт-амперные характеристики скандатных катодов}

При активировании металлопористого катода на основе алюмината бария-кальция в нем формируются кристаллиты оксида бария и кальция, содержащие кислородные вакансии, в результате взаимодействия алюмината с вольфрамом с образованием летучего оксида вольфрама. Так как в системе „оксид алюминия-оксид бария-оксид кальция“ существует несколько сложных оксидов, то ее взаимодействие с вольфрамом можно записать в виде суммарной реакции

$$
\begin{aligned}
& m \mathrm{BaO} \cdot n \mathrm{CaO} \cdot \mathrm{Al}_{2} \mathrm{O}_{3}+\mathrm{W} \\
& \rightarrow(m-1) \mathrm{BaO} \cdot(n-1) \mathrm{CaO} \cdot \mathrm{Al}_{2} \mathrm{O}_{3}+\mathrm{BaO}_{1-x} \\
& +\mathrm{CaO}_{(1-x)}+\mathrm{WO}_{3} \uparrow .
\end{aligned}
$$

В скандатном катоде на основе алюмината бариякальция, содержащего дополнительно скандийсодержащие компоненты, образующиеся кристаллиты оксида бария могут дополнительно содержать легирующие примесные атомы скандия. В работе [9] было показано, что из-за различия энергии Гиббса образования оксидов бария и кальция, кислород может „перетекать“ между кристаллитами оксида бария и оксида кальция, содержащих кислородные вакансии.

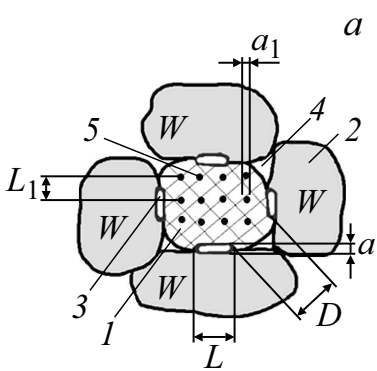

$b$

Рис. 8. Структура поверхности скандатного катода (a) и структура эмиттирующих доменов на его поверхности $(b)$.

Если скандатный катод выполнен на основе скандата бария-кальция, то в результате протекания твердофазной реакции типа (18), но с заменой алюмината бариякальция на скандат бария-кальция, в катоде также образуются кристаллиты оксида бария и оксида кальция, при этом концентрация кислородных вакансий в кристаллитах оксида бария будет меньше, чем при образовании их из алюмината бария-кальция [9]. Поэтому скандатные катоды с „рекордными“ эмиссионными характеристиками выполняют на основе алюмината бариякальция, содержащего дополнительно 3-5\% оксида или интерметаллида скандия, с дополнительным нанесением на поверхность катода, например методом лазерного распыления соответствующей мишени, пленки состава $\mathrm{W}+5 \% \mathrm{Sc}_{2} \mathrm{O}_{3}$ [4]. Такая технология обеспечивает формирование на поверхности алюмината нанокристаллитов вольфрама и оксида скандия, которые инициируют формирование нанокристаллитов оксида бария, содержащих легирующие примеси скандия, по реакции (18).

На рис. 8, $а$ приведена структура поверхности скандатного катода, а на рис. $8, b-$ структура доменов, сформировавшихся на поверхности нанокристаллитов оксида бария. На рисунках обозначено: 1 - зерна алюмината, 2 - зерна вольфрама, 3 - зерна оксида бария на границе металлической и алюминатной фаз, 4 - поры, 5 - нанокристаллиты оксида бария на алюминате, сформировавшиеся в виде структуры 5.1 на бездефектной поверхности алюмината или в виде структуры 5.2 на дефекте в алюминате, 6 - скандийсодержащие домены на нанокристаллитах 5.1 и 5.2, 7 - дефект в алюминате в виде дислокации, микротрещины, границы зерен, $D$ - среднее расстояние между кристаллитами оксида бария на границе вольфрама и алюмината, $а$ и $L-$ средние размеры этих кристаллитов, $a_{1}$ и $L_{1}-$ соответственно средний размер нанокристаллитов типа 5 и среднее расстояние между ними, $H$ - средняя высота нанокристаллитов типа 5.1 или 5.2.

При экспериментальном определении работы выхода скандатных катодов из-за их высокой эмиссионной способности обычно вызывает затруднение определение плотности тока насыщения при конкретной температуре катода и последующий расчет по этому значению величины работы выхода материала катода методом „полно- 
го тока“ при неопределенности эффективной площади эмиттирующей поверхности. Поэтому вольт-амперные характеристики катодов такого типа часто анализируют при напряжении катод-анод $U$ вблизи области ограничения тока катода $I$ пространственным зарядом. Так как в области ограничения тока пространственным зарядом вольт-амперная характеристика имеет вид прямой в координатах $I-U^{3 / 2}$, то за величину тока насыщения в области действия эффекта Шоттки принимают либо ток, отличающийся на $10 \%$ от указанной прямой, либо ток при пересечении вольт-амперной характеристики в данной области с прямой, имеющей 73\% наклона от прямой для области ограничения тока пространственным зарядом [15]. Очевидно, что такие критерии не являются физически и теоретически обоснованными.

Вид вольт-амперной характеристики катода в области насыщения тока зависит от двух факторов: коэффициента усиления поля у поверхности центров термоэмиссии, который в свою очередь зависит от формы и размеров эмиттирующих центров [16], и от дрейфа и диффузии кислородных вакансий в кристаллитах и нанокристаллитах оксида бария, которые зависят от толщины эмиттирующих центров и коэффициента диффузии кислородных вакансий, зависящего в свою очередь от наличия или отсутствия упорядочения кислородных вакансий [17].

Величину эффективной работы выхода материала $\varphi_{\text {eff }}$ при наличии у его поверхности электрического поля $E$ можно представить в виде [16]

$$
\varphi_{\mathrm{eff}}=\varphi(A, B, C, D)-e\left[\frac{e(s+1) K}{4 \pi s_{0}(s-1)}\right]^{1 / 2} \cdot E^{1 / 2},
$$

где $\varphi(A, B, C, D)$ - истинная работы выхода для рассмотренных выше вариантов структур $A, B, C, D, K-$ коэффициент усиления поля у поверхности эмиттирующих центров.

В рамках первого фактора, влияющего на вид вольтамперной характеристики, для областей 3 на рис. 8, а величина коэффициента усиления поля $K_{1}$ равна

$$
K_{1}=2 d / a \cdot \ln (2 d / a),
$$

где $d-$ расстояние катод-анод. Для областей 5 на рис. $8, b$ величину коэффициента усиления поля $K_{2}$ с учетом расчетов, приведенных в работе [18], можно представить в виде

$$
K_{2}=\beta H / a_{1},
$$

где параметр $\beta-$ не сильно отличается от единицы и зависит от соотношения значений диэлектрической проницаемости областей 1 и 5.1 или 5.2 на рис. $8, b$.

В процессе работы скандатного катода величина $K_{1}$ будет изменяться не очень сильно, при этом области 3 будут вносить незначительный вклад в общий ток термоэмиссии катода из-за более высокой работы выхода для варианта структуры $A$ по сравнению с вариантами структуры $B$ и $C$. Однако величина $K_{2}$, которая относится к нанокристаллитам оксида бария, в процессе работы скандатного катода может изменяться весьма значительно. Указанный параметр для области 5.2 будет больше, чем для области 5.1, при этом из-за диффузионных процессов по элементам структуры 7 на рис. 8, $b$ для структуры 5.2 он будет изменяться сильнее, чем для структуры 5.1 .

Второй фактор, влияющий на вид вольт-амперной характеристики, проявляется в виде спада тока термоэмиссии по времени или с увеличением напряжения катоданод [17]. Для областей 3 на рис. 8, $a$ его проявление будет незначительным из-за отсутствия упорядочения кислородных вакансий в кристаллитах оксида бария при отсутствии растворенных в них атомов скандия, а также из-за сравнительно большой толщины области 3, составляющей $1-2 \mu \mathrm{m}$ [17]. В то же время для нанокристаллитных структур 5.1 и 5.2 на рис. $8, b$ наличие растворенных атомов скандия в нанокристаллитах приводит к увеличению коэффициента диффузии кислорода из-за упорядочения кислородных вакансий, а изменение параметра $H$ в процессе работы катода - к усилению эффекта спада тока.

С учетом вышеизложенного корректное определение работы выхода скандатных катодов может быть проведено с использованием комплексной методики, предложенной в работах $[16,17]$ при цифровой регистрации вольт-амперных характеристик в области ограничения тока пространственным зарядом с шагом $0.1-0.2 \mathrm{~V}$ и в области действия эффекта Шоттки с шагом 2-5 V. Методика позволяет определять параметры $a_{1}, H$ и $L_{1}$ для доменов на поверхности скандатных катодов, рассчитать эффективную площадь эмиттирующей поверхности катода и далее рассчитать параметры $K_{2}, \varphi(A, B, C, D)$ и $\varphi_{\text {eff. }}$ Анализ динамики изменения параметров $K_{2}, a_{1}, H$ и $L_{1}$ при активировании и на сроке службы скандатного катода позволяет оптимизировать технологию изготовления таких катодов.

\section{Заключение}

Формирование скандатного катода с высокой плотностью тока термоэлектронной эмиссии возможно путем формирования на поверхности алюминатной фазы катода нанокристаллитов вольфрама и скандийсодержащего компонента (оксид скандия или интерметаллид скандия), которые обеспечивают в свою очередь формирование на поверхности алюминатной фазы нанокристаллитов оксида бария, содержащих кислородные вакансии и легирующие атомы скандия.

В зависимости от размеров сформировавшихся нанокристаллитов оксида бария на их поверхности могут формироваться домены различных типов, поверхность которых обогащена скандием.

Величина работы выхода доменов зависит от их типа, т.е. фактически от размера нанокристаллитов оксида 
бария, и может изменяться в зависимости от технологии изготовления катода, режима его активирования и режима эксплуатации катода.

Плотность тока термоэмиссии нанокристаллитных структур, содержащих на поверхности домены на основе примесных атомов скандия, с учетом усиления тока термоэмиссии вследствие эффекта Шоттки может достигать $300-500 \mathrm{~A} / \mathrm{cm}^{2}$ в интервале температур 900-1000 ${ }^{\circ} \mathrm{C}$.

Анализ вольт-амперных характеристик скандатного катода и анализ характера спада тока термоэмиссии, измеренных с малым шагом изменения напряжения катод-анод, позволяет определить основные параметры эмиссионно-активных доменов - их тип и геометрические характеристики, т. е. в конечном счете, оптимизировать технологию изготовления скандатного катода.

\section{Конфликт интересов}

Авторы заявляют, что у них нет конфликта интересов.

\section{Список литературы}

[1] Дюбуа Б.Ч., Поливникова О.В. // Электронная техника. Сер. 1. СВЧ-техника. 2013. Вып. 4 (519). С. 187-190.

[2] Дюбуа Б.Ч., Королев А.Н. // Электронная техника. Сер. 1. СВЧ-техника. 2011. Вып. 1 (509). С. 5-25.

[3] Schoenbeck Laura // In Partial Fulfillment of the Requirements for the Degree Master of Science in Materials Science and Engineering. USA. Georgia Institute of Technology, February 2005. 118 p.

[4] Gartner G., Geintter P., Ritz A. // Appl. Surf. Sci. 1997. N 111. P. 11-17.

[5] Brodie I., Vancil B. // Proc. IEEE Int. Vacuum Electronics Conf., Monterey, CA, United States, 2014. P. 53-54.

[6] Bekh I.I., Getman O.I., Il'chenko V.V., Lushkin A.E., Panichkina V.V., Rakitin S.P. // Ukr. J. Phys. 2009. Vol. 54. N 3. P. 297-302.

[7] Капустин В.И. // Изв. АН СССР. Сер. Физ. 1991. Т. 55. № 12. C. $2455-2458$.

[8] Капустин В.И. // Перспективные материалы. 2000. № 2. C. 5-17.

[9] Капустин В.И., Ли И.П., Шуманов А.В., Лебединский Ю.Ю., Заблочкий А.В. // ЖТФ. 2017. Т. 87. Вып. 1. C. 105-115. [Kapustin V.I., Li I.P., Shumanov A.V., Lebedinskii Yu.Yu., Zablotskii A.V. // Tech. Phys. 2017. Vol. 62. N 1. P. 116-126.]

[10] Капустин В.И., Ли И.П., Петров В.С., Леденцова Н.Е., Турбина А.В. // Электронная техника. Сер. 1: СВЧтехника. Вып. 1 (528). 2016. С. 8-18.

[11] Brodie I., Vancil B. // Proc. IEEE Int. Vacuum Electronics Conf., Monterey, CA, United States, 2014. P. 53-54.

[12] Физико-химические свойства окислов: Справочник / Самсонов Г.В., Борисова А.Л., Жидкова Т.Г. идр. М.: Металлургия, 1978. $472 \mathrm{c.}$

[13] Glasstone S., Laidler K.J., Eyring H. The Theory of Rate Processes / Princeton University. N. Y.\& London. N 1941. [Глестон С., Лейдлер К., Эйринг Г. Теория абсолютных скоростей реакций / Пер. с англ. М.: ИЛ, 1948. 584 с.]
[14] Davison S.G., Levine J.D. Surface states. Academic Press. N.Y., London, 1970. [Дэвисон С., Левин Джс. Поверхностные (Таммовские) состояния / Пер. с англ. М.: Мир. 1973. 232 c.]

[15] Raju R.S., Maloney C.E. // IEEE Trans. El. Dev. 1994. Vol. 41. N 12. P. $134-145$.

[16] Капустин В.И., Ли И.П., Шуманов А.В. // ЖТФ. 2018. T. 88. Вып. 3. С. 472-478. [Kapustin V.I., Li I.P., Shumanov A.V. // Tech. Phys. 2018. Vol. 63. N 3. P. 460-466.]

[17] Капустин В.И., Ли И.П., Шуманов А.В. // Письма в ЖТФ. 2017. Т. 43. Вып. 12. С. 12-20. [Kapustin V.I., Li I.P., Shumanov A.V. // Tech. Phys. Lett. 2017. Vol. 43. N 10. P. 875-878.]

[18] Бельский М.Д., Бочаров Г.С., Елецкий А.В., Sommerer T.J. // ЖТФ. 2010. Т. 80. Вып. 2. С. 130-137. 